\title{
Discussion on the application of computer multimedia in College Physical Education
}

\author{
Weibo Zhou \\ jiangxi police college, Nanchang, 330103, Jiangxi
}

Key words: multimedia; physical education; application

Abstract: with the rapid development of computer and multimedia, physical education is also in line with the trend of the times. The purpose is to promote the application of multimedia technology in the teaching of physical education. In this paper, the definition of computer multimedia technology, multimedia teaching mode inherent weaknesses, to the impact of sports teaching, multimedia teaching in physical education the problems existing in the process of discussion, and points out some strategies for the application of multimedia technology in the teaching of physical education. Hope to provide reference for relevant research.

Twenty-first Century is the era of large-scale scientific development. Under the influence of the rapid development of science and technology, people are also pursuing the synchronous improvement of the quality of life. The development and application of new technologies has brought an impact on the use of the old mode of operation of the industry. Nowadays, it is difficult for teachers to find teaching methods such as chalk and blackboard. The vast majority of people believe that the application of multimedia technology brings convenience to life, work and study.

1.Definition of computer multimedia technology

The fastest and most flexible technology in the field of information technology is computer multimedia technology. Multimedia technology is a computer, voice, text, images, animation, video and communications functions in one of the electronic technology. With the high speed information network, it can make the computer network and information resources sharing, so it is widely used in service, education, medical, military, financial and other industries.

2 weaknesses inherent in the teaching model

2.1 students lack of interest in active learning

In the past, some students think that physical education class is just to get the results of the curriculum, and then produce boredom, lost interest in learning. Secondly, the students ability to understand the different causes the inconsistent learning effect, only teachers' unilateral explanation and demonstration can not achieve the ideal effect of classroom teaching, classroom full of monotonous and boring tone, make the classroom lose vitality [1].

2.2 classroom teaching effect is not ideal

Some sports include difficult technical moves. In the inherent teaching mode, teachers are often difficult to explain and demonstrate to the students because of the restriction of the site and the unclear explanation. Usually these technical actions to be repeated practice to master. Even if the teacher has made the demonstration, but the student is difficult to achieve the familiar degree to the brief demonstration movement, causes the student to be difficult to form the movement memory in the mind, causes the classroom instruction effect not to be ideal.

2.3 hard and difficult to understand 
In some sports, part of the technical action is regarded as the key difficulty in the project, can not be properly understood. To teach the students the knowledge cannot be internalized, one aspect that affects the progress of teaching, on the other hand also let students feel confused.

3 the influence of multimedia on Physical Education

3.1 arouse students' interest in learning

Einstein once said, "interest is the best teacher." Thus, it can be seen that the interest occupies in the study. Under the premise of interest, the students' learning efficiency will be further improved. The application of multimedia in physical education classes, sounds, images and text into one, bring vitality to the original class will be tedious dull as ditch water, through the knowledge of multimedia courseware is presented to students, to enable the students to understand and summarize. To a large extent, the students' interest in learning.

\section{2 targeted guidance}

The use of multimedia can be used to capture, playback of the characteristics of the movement to master the skills of good or poor students to learn, n./ contrast. Let the students know more about their own problems, effectively correct the students' mistakes, help students to improve their ability.

3.3 to improve the quality of teaching and breakthrough teaching difficulties

The teaching of multimedia technology can present the teaching materials to the students directly. The use of sound, images, text to explain the students, the students to learn the process of establishing the correct concept. With the teacher's demonstration to explain, so that students can correct errors in a timely manner, students can practice targeted exercises, can quickly grasp the sports technology. At the same time, it can help teachers to create excellent teaching situation and achieve the goal of breaking through teaching. The teaching of the major difficulties in a timely and effective solution to the students to learn new knowledge to remove difficulties.

4 problems in the process of multimedia teaching

The 4.1 part of the school without multimedia facilities

Physical education is basically completed in the outdoors, but the establishment of multimedia facilities in the room. Part of the school because there is no problem of construction funds or the number of students and the construction of sports venues indoor excess, which makes the introduction of multimedia facilities problems; from another point of view, some schools do not attach importance to the development of students' sports, resulting in capital investment cannot give enough funds to support multimedia technology.

4.2 full use of multimedia technology teaching

Part of the physical education teachers can not integrate traditional teaching and multimedia teaching, in the process of classroom teaching in the use of multimedia technology, lack of knowledge of the students' learning feedback. Physical education classroom teaching of physical activity knowledge needs to be carefully explained and more practice, always keep the students as the center of classroom teaching, give students enough time and space to understand what they have learned.

\section{3 lack of heuristic teaching}

In the traditional teaching, teachers often use the way to ask questions to test whether the students understand the knowledge correctly, and use the heuristic to guide students to learn [2]. In the multimedia teaching, some teachers of the key and difficult point in teaching also show students to a certain extent, is not easy to cause the students' thinking, all the class teacher is a person oriented, to communicate effectively with students, make students' imagination and creativity to play out in the classroom. 


\section{Application of multimedia technology in Physical Education}

5.1 emphasize the dominant position of students

No matter what kind of teaching methods, the ultimate goal is to contribute to the improvement of teaching efficiency. Multimedia technology teaching is an effective means to promote the effectiveness of physical education teaching. The physical education teachers should make the students better accept the new knowledge and arouse the students' imagination and creativity before making courseware.

5.2 understanding of multimedia teaching and other teaching links

The emergence of multimedia teaching technology in a certain sense to solve the difficulties in teaching, improve teaching efficiency. But we can not say that multimedia technology can replace the other teaching methods. Only by combining a variety of means to complement each other in order to obtain the most effective teaching effect.

5.3 regular production courseware research activities, the establishment of the production team

The quality of teaching courseware has a direct impact on the effectiveness of multimedia teaching. If all the teachers are devoted to the making of courseware, teachers undoubtedly brought great burden at the same time, because of the use of computer teachers of different levels, often make the courseware material is in inferior level. In view of this, the school teaching and research activities should be regularly held the courseware, or set up a special studio, organization of teaching experience, computer high level teachers courseware group composition.

5.4 multimedia technology extension

PE teachers should keep up with the pace of the times, strengthen the study of multimedia technology, devote themselves to teaching, and constantly improve their own quality. Skilled use of multimedia technology, in order to better play an effective role in the teaching process, so that the use of multimedia technology to maximize the use of auxiliary performance.

\section{Conclusion}

The key of multimedia technology in physical education is obvious. The use of multimedia technology in teaching, teachers should also keep their knowledge on the synchronization of information literacy, only a clear understanding of the inherent relation between multimedia teaching and sports teaching, application of multimedia technology can be more effective for teaching contributions.

To sum up, twenty-first Century is a highly internationalized, scientific and diversified era of knowledge economy. The combination of computer multimedia and physical education, has been deeply influencing and changing the traditional concept of education, education, education mode and education method, modern sports teaching reform in a new and effective way of teaching. It plays a very good role in promoting the development of students' basic knowledge of physical education, updating the concept of sports, improving sports skills and improving the quality of thinking. It is to optimize the PE teaching, to stimulate students' motivation and interest in sports learning, enhance the students on the concept of action and physical understanding of the theory of knowledge, promote the optimization of explanation, demonstration, demonstration, operation, evaluation and feedback of sports teaching, it is of great significance to improve the teaching quality of physical education. Looking into the future, the application of computer multimedia in modern physical education has become an inevitable trend, it will have an unprecedented impact on the development of China's sports education. Physical education teachers must seize the pulse of the times, through their own efforts and exploration, as soon as possible to adapt to this new teaching model. In a 
nutshell, PE teachers should accept the computer multimedia teaching concept to develop and advance the vision, but also to the traditional sports teaching mode with a positive attitude and a solid, so that the two interact, develop and complement each other.

\section{References}

[1] Fang Jie, Chen Zhangyu. Application of computer multimedia in physical education teaching [J]. Journal of Fujian Normal University,, 2013,05:82-84+98.

[2]. [J]. in the Yellow application of multimedia computer aided teaching in sports teaching Chinese new products and technology, 2012,01:239.

[3] Zhang Jisheng, Wu Xiaoyang; Wang flew, to explore the application of CAI in the teaching of college sports [J]; Journal of Jiaxing University; 200304

[4] Fang Bin; the manufacture and application of electronic teaching materials of track and field technique [J] Journal of Anhwei Normal University (NATURAL SCIENCE EDITION); 200402

[5] Li Xiaoyan, Yang Yufei, Li Haijun; martial arts teaching reform attempt of "three" primary Changquan CAI Courseware Research and discussion of [J]; Journal of Beijing Sport University; 200102

Chen Rong, Terry Chui,, and [6]; current situation and Prospect of multimedia and network assisted teaching in College Physical Education [J]; Journal of Beijing Sport University; 200402

[7] Zhang Jianping; the integration of computer technology and physical education in Colleges and universities [J]; Journal of Beijing Sport University; 200205 